ARTICLE

\title{
Atomic and electronic structures of an extremely fragile liquid
}

Shinji Kohara1,2, Jaakko Akola3,4,5, Leonid Patrikeev3,6, Matti Ropo ${ }^{3,4}$, Koji Ohara1, Masayoshi Itou', Akihiko Fujiwara ${ }^{1,2}$, Jumpei Yahiro ${ }^{1,7}$, Junpei T. Okada ${ }^{8}$, Takehiko Ishikawa ${ }^{8}$, Akitoshi Mizuno9 Atsunobu Masuno ${ }^{10}$, Yasuhiro Watanabe ${ }^{10} \&$ Takeshi Usuki ${ }^{11}$

The structure of high-temperature liquids is an important topic for understanding the fragility of liquids. Here we report the structure of a high-temperature non-glass-forming oxide liquid, $\mathrm{ZrO}_{2}$, at an atomistic and electronic level. The Bhatia-Thornton number-number structure factor of $\mathrm{ZrO}_{2}$ does not show a first sharp diffraction peak. The atomic structure comprises $\mathrm{ZrO}_{5}, \mathrm{ZrO}_{6}$ and $\mathrm{ZrO}_{7}$ polyhedra with a significant contribution of edge sharing of oxygen in addition to corner sharing. The variety of large oxygen coordination and polyhedral connections with short $\mathrm{Zr}-\mathrm{O}$ bond lifetimes, induced by the relatively large ionic radius of zirconium, disturbs the evolution of intermediate-range ordering, which leads to a reduced electronic band gap and increased delocalization in the ionic $\mathrm{Zr}-\mathrm{O}$ bonding. The details of the chemical bonding explain the extremely low viscosity of the liquid and the absence of a first sharp diffraction peak, and indicate that liquid $\mathrm{ZrO}_{2}$ is an extremely fragile liquid.

\footnotetext{
${ }^{1}$ Research and Utilization Division, Japan Synchrotron Radiation Research Institute/SPring-8, 1-1-1 Kouto, Sayo-cho, Sayo, Hyogo 679-5198, Japan. ${ }^{2}$ Schools of Materials Science, Japan Advanced Institute of Science and Technology, Nomi, Ishikawa 923-1291, Japan. ${ }^{3}$ Department of Physics, Tampere University of Technology, PO Box 692, Fl-33101 Tampere, Finland. ${ }^{4}$ COMP Centre of Excellence, Department of Applied Physics, Aalto University, FI-00076 Aalto, Finland. ${ }^{5}$ Peter-Grünberg-Institut PGI-1, Forschungszentrum Jülich, D-52425 Jülich, Germany. ${ }^{6}$ Department of Mathematics and Physics, Faculty of Technology, Lappeenranta University of Technology, PO Box 20, FI-53851 Lappeenranta, Finland. ${ }^{7}$ Department of Condensed Matter Chemistry and Physics, Graduated School of Sciences, Kyushu University, Fukuoka 812-8581, Japan. ${ }^{8}$ Institute of Space and Astronautical Science (ISAS), Japan Aerospace Exploration Agency (JAXA), Tsukuba, Ibaraki 305-8505, Japan. ${ }^{9}$ Department of Physics, Gakushuin University, Toshima-ku, Tokyo 171-8588, Japan. ${ }^{10}$ Institute of Industrial Science, The University of Tokyo, Meguro-ku, Tokyo 153-8505, Japan. ${ }^{11}$ Graduate School of Science and Engineering, Yamagata University, Yamagata $990-$ 8560, Japan. Correspondence and requests for materials should be addressed to S.K. (email: kohara@spring8.or.jp).
} 
G lass formation from liquid has been studied extensively, and several theories of glass formation were established in the last century. Zachariasen ${ }^{1}$ and $S^{2}{ }^{2}$ proposed the basic concepts of glass formation by classifying constituents into glass formers, glass modifiers and intermediates. Furthermore, Angell ${ }^{3}$ introduced the concept of 'fragility' in glass-forming liquids (GFL) on the basis of the relationship between glass transition temperature and viscosity: liquids can be classified as 'strong' and 'weak' according to their glass-forming ability. Numerous structural studies on liquids and glasses have been performed both experimentally and theoretically ${ }^{4,5}$. The advent of advanced synchrotron/neutron sources and the development of high-performance computers have led to great progress in understanding liquid and glass structure $e^{4,5}$. The structural analysis of liquids with high melting points has been advanced significantly with the invention of the levitation technique ${ }^{6}$, especially in combination with diffraction techniques ${ }^{6}$. The structure of a typical non-GFL, liquid (l-) $\mathrm{Al}_{2} \mathrm{O}_{3}$ and its undercooled liquid have been studied extensively by X-ray diffraction $^{7-9}$, neutron diffraction ${ }^{9,10}$ and molecular dynamics (MD) simulations $8,9,11,12$.

$\mathrm{ZrO}_{2}$ is one representative of non-glass formers and there are few reports about binary ${ }^{13}$ and ternary ${ }^{14}$ glass formation including $\mathrm{ZrO}_{2}$. Moreover, $\mathrm{ZrO}_{2}$ is commonly used as a refractory material and nucleating agent ${ }^{15}$ in the production of glass ceramics, suggesting that $l-\mathrm{ZrO}_{2}$ is indeed a non-GFL. As $\mathrm{ZrO}_{2}$ has an extremely high melting point $\left(T_{\mathrm{m}}=2,715^{\circ} \mathrm{C}\right)$, the difficulties in handling the liquid at high temperatures lead to problems in selecting suitable container materials that avoid contamination effects. We have developed a beamline levitation furnace that enables us to perform precise synchrotron X-ray diffraction measurements of liquids at extremely high temperatures.

We report here the results of precise high-energy X-ray diffraction and density measurements on containerless levitated $l$ $\mathrm{ZrO}_{2}$. We also carry out large-scale density functional (DF)-MD simulations, to understand the liquid properties at the atomistic and electronic level, and we compare $l-\mathrm{ZrO}_{2}$ with other non-GFLs and a typical GFL, $l-\mathrm{SiO}_{2}$. The combination of experiment and theory allows us to identify trends in single-component non-glass-forming oxide liquids, with particular focus on short- and intermediate-range ordering, the electronic band gap, maximally localized Wannier functions (WFs) of the highest valence band orbitals, and viscosity. Furthermore, we compare features of single-component non-glassforming oxide liquids with those of other systems.

\section{Results}

Structure factors and real-space functions. Faber-Ziman ${ }^{16}$ total structure factors, $S(Q)$, for $l-\mathrm{ZrO}_{2}$ at $2,600{ }^{\circ} \mathrm{C}-2,800{ }^{\circ} \mathrm{C}$ are shown in Fig. 1a. The structural change between the liquid at $2,800^{\circ} \mathrm{C}$ and the undercooled liquid at $2,600^{\circ} \mathrm{C}$ is very small. A sharp peak is observed at $Q=2 \AA^{-1}$. The total correlation functions, $T(r)$, for $l-\mathrm{ZrO}_{2}$ (Fig. 1b) show subtle differences in real space as well. The first correlation peak observed at $\sim 2.1 \AA$ is assigned to $\mathrm{Zr}-\mathrm{O}$ correlation and a significant tail to $\sim 3 \AA$ imply the formation of asymmetrical $\mathrm{ZrO}_{n}$ polyhedra in the liquid. The second peak observed at $\sim 3.7 \AA$ can be assigned mainly to $\mathrm{Zr}-\mathrm{Zr}$ correlations and the contribution of $\mathrm{O}-\mathrm{O}$ correlation is unclear due to its small weighting factor $(<10 \%)$ for $\mathrm{X}$-rays. The $\mathrm{Zr}-\mathrm{O}$ correlation length of $2.1 \AA$ is significantly longer than those of $\mathrm{Si}-\mathrm{O}$ $\left(\sim 1.63 \AA^{17}\right.$ at $\left.1,600^{\circ} \mathrm{C}-2,100^{\circ} \mathrm{C}\right)$ and $\mathrm{Al}-\mathrm{O}\left(\sim 1.78 \AA^{9}\right.$ at $2,127^{\circ} \mathrm{C}$ ) due to substantial differences in ionic radius between silicon, aluminum and zirconium ions ${ }^{18}$.

The observed correlation length of $2.1 \AA$ for $\mathrm{Zr}-\mathrm{O}$ agrees well with recent experimental data of Skinner et al. ${ }^{19}$ Furthermore, the increased cation-oxygen correlation length in $l-\mathrm{ZrO}_{2}$ indicates
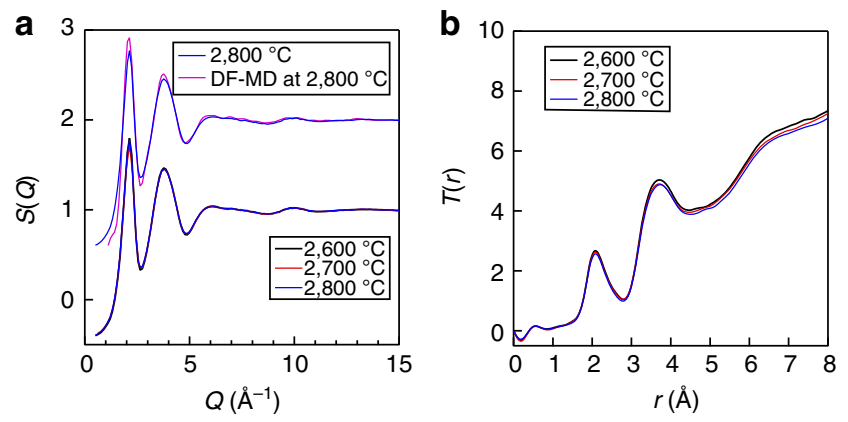

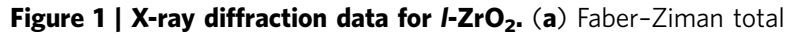
structure factors, $S(Q)$, for $1-\mathrm{ZrO}_{2}$ at $2,600^{\circ} \mathrm{C}-2,800^{\circ} \mathrm{C}$ together with the $S(Q)$ derived from the DF-MD simulation at $2,800^{\circ} \mathrm{C}$. Both the experimental and DF-MD simulation data at $2,800^{\circ} \mathrm{C}$ are displaced upward by 1 for clarity. (b) Total correlation functions, $T(r)$, for $1-\mathrm{ZrO}_{2}$ at $2,600-$ $2,800^{\circ} \mathrm{C}$. The sharp peak observed at $Q=2.1 \AA^{-1}$ in the $S(Q)$ of $I-\mathrm{ZrO}_{2}$ can be assigned to the principal peak reported by Salmon et al. ${ }^{21}$

that the oxygen coordination number around zirconium is $>4$, because $2.1 \AA$ is close to the sum of the ionic radii of oxygen $\left(1.35 \AA^{18}\right)$ and sixfold zirconium $\left(0.72 \AA^{18}\right)$. The intermediaterange structure of $l-\mathrm{ZrO}_{2}$ is then made up of large, interconnected polyhedral units and very different from those of $l-\mathrm{SiO}_{2}$ and $l-\mathrm{Al}_{2} \mathrm{O}_{3}$. This implies that the peak observed at $Q=2 \AA^{-1}$ in the $S(Q)$ in Fig. 1a is not the first sharp diffraction peak (FSDP), which is typically associated with intermediate-range ordering in disordered materials, so that there is no such ordering in $l-\mathrm{ZrO}_{2}$.

The total structure factor, $S(Q)$, obtained from the DF-MD simulations at $2,800^{\circ} \mathrm{C}$ is shown in Fig. 1a as a magenta curve. The agreement with experimental data is excellent. Additional insight into the intermediate-range ordering of $l-\mathrm{ZrO}_{2}$, in comparison with $l-\mathrm{SiO}_{2}$ and $l-\mathrm{Al}_{2} \mathrm{O}_{3}$, can be found by calculating the Bhatia-Thornton ${ }^{20}$ number-number partial structure factor, $S_{\mathrm{NN}}(Q)$,

$$
S_{\mathrm{NN}}(Q)=c_{\mathrm{A}}^{2} S_{\mathrm{AA}}(Q)+2 c_{\mathrm{A}} c_{\mathrm{X}} S_{\mathrm{AX}}(Q)+c_{\mathrm{X}}^{2} S_{\mathrm{XX}}(Q),
$$

where $S_{i j}(Q)$ is a Faber-Ziman partial structure factor (see Supplementary Fig. 1) and $c_{i}$ denotes the atomic fraction of chemical species $i^{2}$. Figure 2a shows $S_{\mathrm{NN}}(Q)$ (see Supplementary Fig. 2) of $l-\mathrm{ZrO}_{2}$ at $2,800{ }^{\circ} \mathrm{C}$ compared with those of $l-\mathrm{Al}_{2} \mathrm{O}_{3}$ at $2,127^{\circ} \mathrm{C}^{9}$ and $l-\mathrm{SiO}_{2}$ at $2,100{ }^{\circ} \mathrm{C}^{22}$. Only $l-\mathrm{SiO}_{2}$ exhibits FSDP at $\mathrm{Qr}_{\mathrm{AX}}=2.7\left(r_{\mathrm{AX}}\right.$ is the atomic cation $(\mathrm{A})$-anion $(\mathrm{X})$ distance in AX polyhedra to normalize $Q$ ). Neither $l-\mathrm{Al}_{2} \mathrm{O}_{3}$ nor $l-\mathrm{ZrO}_{2}$ show an FSDP in the $S_{\mathrm{NN}}(Q)$, whereas it is present in the total X-ray and neutron $S(Q)$ of $l-\mathrm{Al}_{2} \mathrm{O}_{3}$ (see Supplementary Fig. 3$)^{9}$ due to the contribution of weighting factors for X-rays and neutrons. As Bhatia-Thornton $S_{\mathrm{NN}}(Q)$ can eliminate the weighting factors, the absence of FSDP in the $S_{\mathrm{NN}}(Q)$ of $l-\mathrm{ZrO}_{2}$ is a signature of nonglass-forming behaviour.

The partial pair correlation functions, $g_{i j}(r)$, of $l-\mathrm{ZrO}_{2}$ derived from the DF-MD simulations are presented in Supplementary Fig. 4, together with those of the high-temperature phase of crystalline (c-) $\mathrm{ZrO}_{2}$ (ref. 23). The first correlation peak of $g_{\mathrm{ZrO}}(r)$ for $l-\mathrm{ZrO}_{2}$ is broad and shows a tail up to $2.8 \AA$. A very broad first maximum in $g_{\mathrm{OO}}(r)$ overlaps the first correlation peaks of $g_{\mathrm{ZrO}}(r)$ and $g_{\mathrm{ZrZr}}(r)$, indicating that the oxygen coordination is very different from those of $l-\mathrm{SiO}_{2}$ and $l-\mathrm{Al}_{2} \mathrm{O}_{3}$, where corner-sharing tetrahedra are predominant.

Analysis of three-dimensional atomic arrangement. The average coordination number of oxygen around zirconium, $N_{\mathrm{ZrO}}$, 

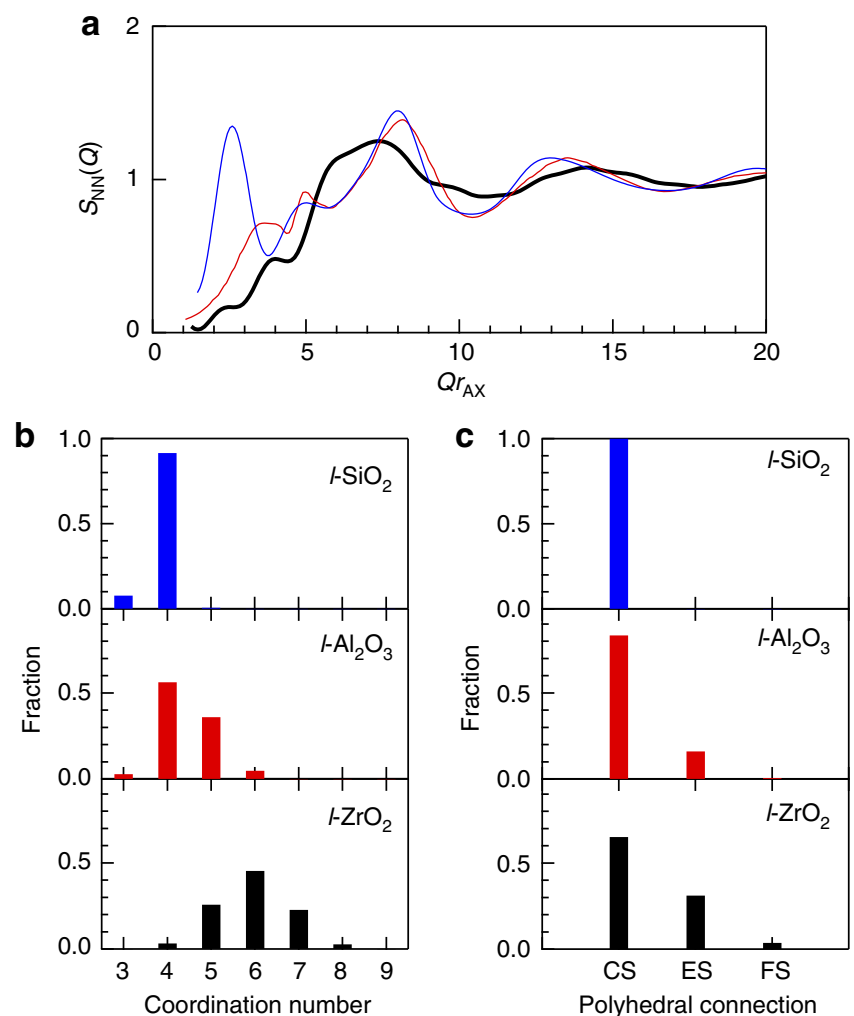

Figure 2 | Comparison of the structural data for oxide liquids. (a) The Bhatia-Thornton number-number partial structure factor, $S_{N N}(Q)$, for 1 $\mathrm{ZrO}_{2}$ at $2,800^{\circ} \mathrm{C}$ derived from the DF-MD simulation (black curve) in comparison with those of $\mathrm{I}-\mathrm{Al}_{2} \mathrm{O}_{3}$ at $2,127^{\circ} \mathrm{C}$ (red curve) ${ }^{9}$ and $\mathrm{I}-\mathrm{SiO}_{2}$ at $2,100^{\circ} \mathrm{C}$ (blue curve) ${ }^{22}$. The momentum transfer $\mathrm{Q}$ was scaled by $r_{A X}$, where $r_{A X}$ is the first coordination distance between $A$ and $X$ in the real-space function. The Bhatia-Thornton concentration-concentration partial structure factor, $S_{C C}(Q)$, and number-concentration partial structure factor, $S_{N C}(Q)$, are shown in Supplementary Fig. 2 together with the detailed note (Supplementary Note 1). (b) The coordination number distribution of oxygen around the cations in $1-\mathrm{ZrO}_{2}$ at $2,800^{\circ} \mathrm{C}, \mathrm{I}-\mathrm{Al}_{2} \mathrm{O}_{3}$ at $2,127^{\circ} \mathrm{C}^{9}$ and $\mathrm{I}-\mathrm{SiO}_{2}$ at $2,100^{\circ} \mathrm{C}^{22}$. (c) The polyhedral connections in $\mathrm{I}-\mathrm{ZrO}_{2}$ at $2,800^{\circ} \mathrm{C}, \mathrm{I}-\mathrm{Al}_{2} \mathrm{O}_{3}$ at $2,127^{\circ} \mathrm{C}^{9}$ and $\mathrm{I}-\mathrm{SiO}_{2}$ at $2,100^{\circ} \mathrm{C}^{22}$. $\mathrm{CS}$, corner sharing of oxygen; $\mathrm{ES}$, edge sharing of oxygen; $\mathrm{FS}$, face sharing of oxygen.

calculated up to $2.8 \AA$ for $l-\mathrm{ZrO}_{2}$ is 5.9 for the DF-MD configuration $\left(N_{\mathrm{OZr}} \sim 3\right)$, significantly lower than 8 in $c-\mathrm{ZrO}_{2}$. Recently, Skinner et al. ${ }^{19}$ reported that $N_{\mathrm{ZrO}}=6.1$ at $2,897^{\circ} \mathrm{C}$, which is close to our value $\left(5.9\right.$ at $\left.2,800^{\circ} \mathrm{C}\right)$, although the estimated density in ref. 19 is smaller than our experimentally measured value. The oxygen coordination number around zirconium is significantly larger than $N_{\mathrm{Si}-\mathrm{O}}=3.9$ in $l-\mathrm{SiO}_{2}$ at $2,100^{\circ} \mathrm{C}^{22}$ and $N_{\mathrm{Al}-\mathrm{O}}=4.4$ in $l$ - $\mathrm{Al}_{2} \mathrm{O}_{3}$ at $2,127^{\circ} \mathrm{C}^{9}$, due to large differences between the ionic radii of $\mathrm{Si}, \mathrm{Al}$ and $\mathrm{Zr}$. Similarly, large oxygen numbers reported on other non-GFLs $\left(N_{\mathrm{Y}-\mathrm{O}}=5.5\right.$ in $l-\mathrm{Y}_{2} \mathrm{O}_{3}$ at $2,597^{\circ} \mathrm{C}^{19}$ and $N_{\mathrm{La}-}$ $\mathrm{O}=5.9$ in $l-\mathrm{La}_{2} \mathrm{O}_{3}$ at $2,497^{\circ} \mathrm{C}^{19}$ ) support our argument that a large oxygen coordination in $l-\mathrm{ZrO}_{2}$ is a signature of non-GFLs and is associated with the absence of FSDP.

The coordination number distributions of $l-\mathrm{SiO}_{2}$ (ref. 22), $l$ - $\mathrm{Al}_{2} \mathrm{O}_{3}$ (ref. 9) and $l-\mathrm{ZrO}_{2}$ calculated from the structural models are shown in Fig. 2b. $\mathrm{SiO}_{4}$ tetrahedra are predominant in $l-\mathrm{SiO}_{2}$ (ref. 22), while $l-\mathrm{Al}_{2} \mathrm{O}_{3}$ comprises $\mathrm{AlO}_{3}, \mathrm{AlO}_{5}$ and $\mathrm{AlO}_{6}$ units, as well as fourfold $\mathrm{Al}$. For $\mathrm{l}-\mathrm{ZrO}_{2}$, the most common configurations are $\mathrm{ZrO}_{5}, \mathrm{ZrO}_{6}$ and $\mathrm{ZrO}_{7}$. Although $\mathrm{ZrO}_{2}$ and $\mathrm{Al}_{2} \mathrm{O}_{3}$ have different stoichiometries, this comparison supports our view that the variety of oxygen coordination around cations in $l-\mathrm{ZrO}_{2}$ is another characteristic feature of non-glass-forming behaviour, because it can disturb the evolution of intermediate-range ordering.

To obtain structural features beyond the first coordination distance, a polyhedral connection analysis for $l-\mathrm{SiO}_{2}$ (ref. 22), $l$ $\mathrm{Al}_{2} \mathrm{O}_{3}$ (ref. 9) and $l-\mathrm{ZrO}_{2}$ has been carried out. Figure $2 \mathrm{c}$ shows the fraction of corner sharing, edge sharing and face sharing of polyhedral units in the liquids. Corner sharing of oxygen is prevalent in $l-\mathrm{SiO}_{2}$ (ref. 22), which is a unique feature of GFLs according to Zachariasen ${ }^{1}$. However, both $l-\mathrm{Al}_{2} \mathrm{O}_{3}$ and $l-\mathrm{ZrO}_{2}$ exhibit a considerable oxygen edge sharing, so that the variety of polyhedral connections is a further characteristic feature of single-component, non-glass-forming oxide liquids.

The bond angle distributions for $l-\mathrm{ZrO}_{2}$ at $2,800{ }^{\circ} \mathrm{C}$ derived from the DF-MD simulations are shown in Fig. 3. The peak at $\sim 105^{\circ}$ in the $\mathrm{Zr}-\mathrm{O}-\mathrm{Zr}$ distribution is very different from that at $\sim 145^{\circ}$ in the $\mathrm{Si}-\mathrm{O}-\mathrm{Si}$ distribution of $l-\mathrm{SiO}_{2}$ (ref. 22), but similar to the $\mathrm{Al}-\mathrm{O}-\mathrm{Al}$ distribution in $\mathrm{l}-\mathrm{Al}_{2} \mathrm{O}_{3}$ (ref. 9). The $\mathrm{O}-\mathrm{Zr}-\mathrm{O}$ distribution shows a principal peak at $75^{\circ}$ and a small peak at $150^{\circ}$. They are very different from the angle of a typical $\mathrm{AX}_{4}$ tetrahedron $\left(109.47^{\circ}\right)$, but similar to the O-Al-O distribution in $l-\mathrm{Al}_{2} \mathrm{O}_{3}$ (ref. 9). This indicates that the wide variation of $\mathrm{ZrO}_{n}$ polyhedra $\left(\mathrm{ZrO}_{5}, \mathrm{ZrO}_{6}\right.$ and $\left.\mathrm{ZrO}_{7}\right)$ is another characteristic feature of $l-\mathrm{ZrO}_{2}$. The distributions of $\mathrm{Zr}-\mathrm{Zr}-\mathrm{Zr}, \mathrm{Zr}-\mathrm{Zr}-\mathrm{O}$ and $\mathrm{O}-\mathrm{O}-\mathrm{Zr}$ are also similar to those of $l-\mathrm{Al}_{2} \mathrm{O}_{3}$ (ref. 9). The O-O-O distribution of $l-\mathrm{ZrO}_{2}$ shows a maximum only at $60^{\circ}$, while the $\mathrm{O}-\mathrm{O}-\mathrm{O}$ distribution of $\mathrm{l}-\mathrm{Al}_{2} \mathrm{O}_{3}$ (ref. 9) has a prominent peak at $60^{\circ}$ and a small but distinct peak at $\sim 110^{\circ}$ (signature of an anion in tetrahedral coordination). However, $l-\mathrm{ZrO}_{2}$ does not have this feature, implying that its oxygen coordination is different.

The bond angle distributions for the high-temperature phase of $c-\mathrm{ZrO}_{2}$ (ref. 23) are shown in Fig. 3 as red lines. Although there are similarities in the liquid and crystal, the most striking difference is in the $\mathrm{O}-\mathrm{O}-\mathrm{O}$ distribution: $l-\mathrm{ZrO}_{2}$ has a prominent peak at $60^{\circ}$, while $c-\mathrm{ZrO}_{2}$ shows intense peaks at $90^{\circ}$ and $174^{\circ}$. This difference is caused by the variation of short-range ordering in the $\mathrm{ZrO}_{n}$ polyhedral units.

Analysis of electronic structure. The electronic structure analysis was performed in terms of the electronic density of states (DOS), WFs and effective charges for snapshots of the high-temperature phases of $c-\mathrm{ZrO}_{2}$ and $l-\mathrm{ZrO}_{2}$. The DOS (above $-20 \mathrm{eV}$ ) of $c$ - and $l-\mathrm{ZrO}_{2}$, and its projections (P-DOS) for $l-\mathrm{ZrO}_{2}$ are shown in Fig. 4a. The P-DOS plots reveal that this part of the electronic spectrum is associated mainly with oxygen (O-2p orbitals) and the $\mathrm{Zr}$ semicore states corresponding to the atomic $\mathrm{Zr}-4 s$ and $\mathrm{Zr}$ $4 p$ orbitals are deeper (below $-20 \mathrm{eV}$, not shown). The zirconium $d$-component dominates in the conduction band of $l-\mathrm{ZrO}_{2}$. The effect of high temperature on the distorted $\mathrm{ZrO}_{n}$ polyhedra in $l-\mathrm{ZrO}_{2}$ is evident as a broadening of the energy bands and the gap between the valence and conduction bands has disappeared (the calculated band gap is $3.26 \mathrm{eV}$ for $c-\mathrm{ZrO}_{2}$ ).

The difference between the electronegativities of $\mathrm{Zr}$ (1.3) and $\mathrm{O}$ (3.5) indicates that the chemical bonding between the two elements is mainly ionic and this is supported by the significant weight on oxygen P-DOS for the highest valence band. Table 1 summarizes the atomic charges and volumes of $\mathrm{Zr}$ cations and $\mathrm{O}$ anions in $c$ - and $l-\mathrm{ZrO}_{2}$ obtained by the Bader method ${ }^{24}$. For $l-\mathrm{ZrO}_{2}$, the evaluated effective charges are $+2.62 e$ and $-1.31 e$ for $\mathrm{Zr}$ and $\mathrm{O}$, respectively, and reflect the ionic bonding. The atomic charges in $l-\mathrm{ZrO}_{2}$ are very similar to those in the crystalline phase, which is in accordance with our previous studies on $\mathrm{MgO}-\mathrm{SiO}_{2}$ (ref. 25) and $\mathrm{CaO}-\mathrm{Al}_{2} \mathrm{O}_{3}$ (ref. 26) glasses. The associated atomic volumes imply that the increased oxygen volume in $l-\mathrm{ZrO}_{2}$ compensates for the decreased oxygen coordination, and this results in comparable 

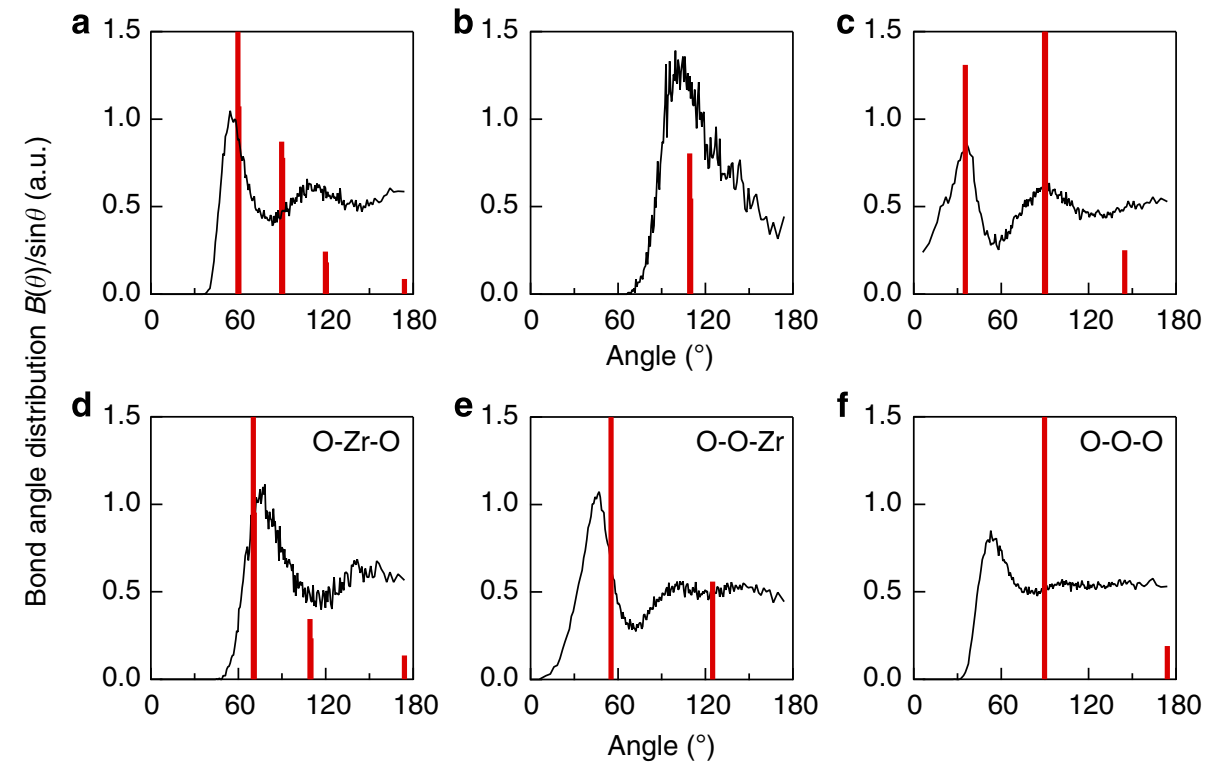

Figure 3 | Bond angle distributions for $\mathbf{I}_{\mathbf{Z r O}}$ at $\mathbf{2 , 8 0 0}{ }^{\circ} \mathbf{C}$ and $\mathbf{c}-\mathrm{ZrO}_{\mathbf{2}}$. (a) The bond angle configurations $\mathrm{Zr}-\mathrm{Zr}-\mathrm{Zr}$, (b) $\mathrm{Zr}-\mathrm{O}-\mathrm{Zr}$, (c) $\mathrm{Zr}-\mathrm{Zr}-\mathrm{O},(\mathbf{d}) \mathrm{O}-\mathrm{Zr}$ $\mathrm{O}$, (e) $\mathrm{O}-\mathrm{O}-\mathrm{Zr}$ and (f) $\mathrm{O}-\mathrm{O}-\mathrm{O}$. The $\mathrm{B}(\theta) / \sin \theta$ data for $\mathrm{c}-\mathrm{ZrO}_{2}$ has been scaled by a factor of 20 for clarity.
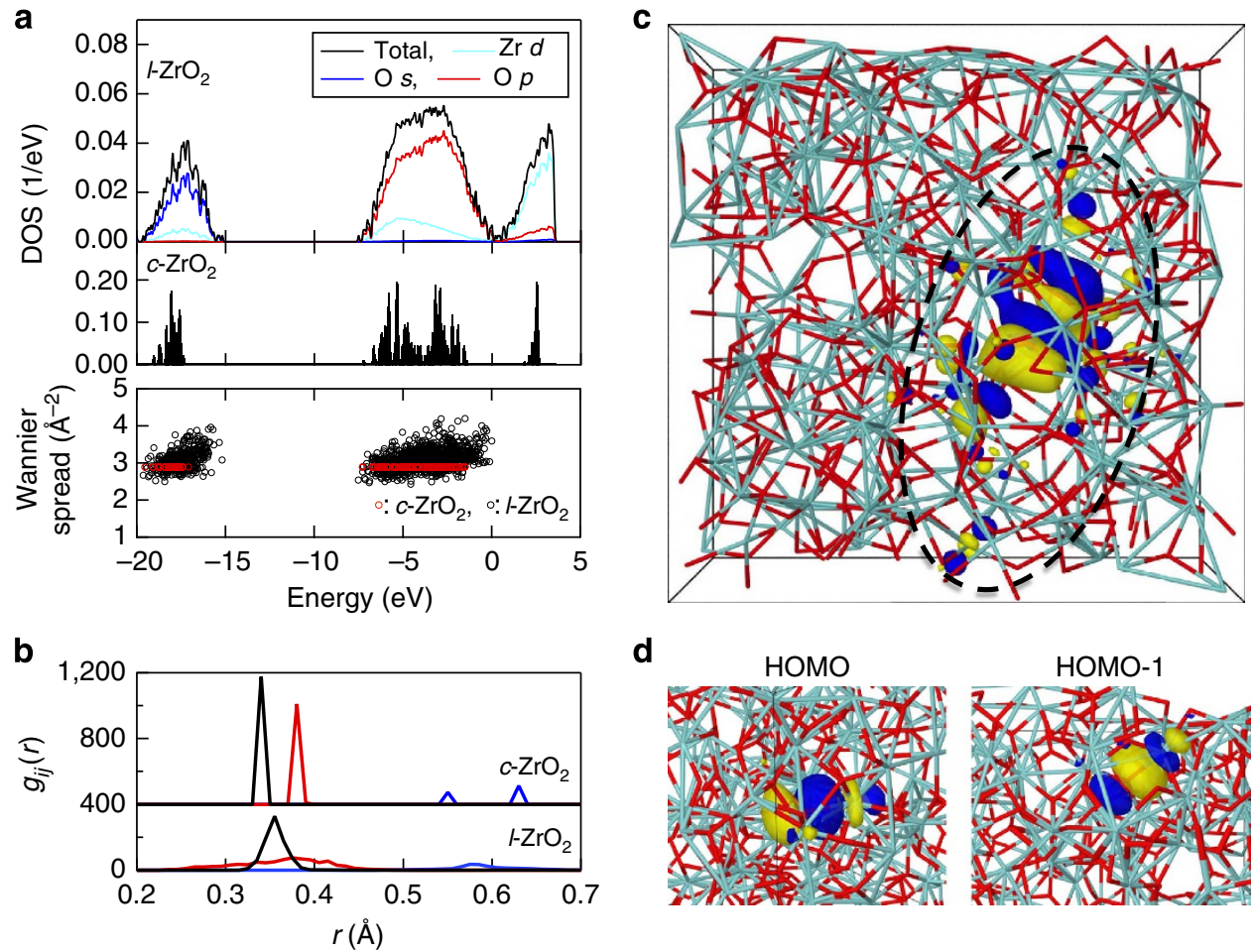

Figure 4 | The electronic structure of $\mathbf{c}-\mathbf{Z r O}_{\mathbf{2}}$ and $\mathbf{I - Z r O} \mathbf{Z}_{2}$. (a) DOS and its projections onto atomic orbitals for the higher valence bands and conduction band, together with the Wannier function spreads (occupied states). (b) The partial pair correlation functions, $g_{i j}(r)$, of WF centres, $Z r-C_{w}$ (black), O- $C_{w}$ (red) and $\mathrm{C}_{\mathrm{w}}-\mathrm{C}_{\mathrm{w}}$ (blue). (c) A visualization of the $\mathrm{HOMO}$ state (KS orbital) in $\mathrm{I}-\mathrm{ZrO}_{2}$. (d) Two WFs corresponding to $\mathrm{HOMO}$ and $\mathrm{HOMO}-1$ of $\mathrm{I}-\mathrm{ZrO} \mathrm{Z}_{2}$. $\mathrm{Zr}$ and $\mathrm{O}$ atoms are shown in cyan and red colour, respectively. Yellow and blue isosurfaces denote different signs of the wavefunction nodes.

Table 1 | Atomic charges and volumes obtained by the Bader method.

\begin{tabular}{|c|c|c|c|c|}
\hline$c-\mathrm{ZrO}_{2}$ & 2.60 & 10.54 & -1.30 & 11.65 \\
\hline
\end{tabular}


atomic charges for the two phases. Similar behaviour has been found for $\mathrm{MgO}-\mathrm{SiO}_{2}$ glass ${ }^{25}$.

The maximally localized WF can be considered as the natural generalization of 'localized molecular orbitals' in solids and they provide valuable insight into chemical bonding 27,28 . The WFs have been obtained from the occupied Kohn-Sham (KS) orbitals by a unitary transformation where the spatial extension (spread) of the WF orbitals is minimized. For each WF orbital, the Wannier centre $\left(C_{\mathrm{w}}\right)$ location denotes the most probable point for locating an electron (or electron pair in case of a spin-degenerate orbital) and the corresponding Wannier spread is a direct measure of the degree of localization. The distribution of Wannier spreads and $C_{\mathrm{w}} \mathrm{s}$ in terms of pair correlation functions are shown in Fig. $4 \mathrm{a}, \mathrm{b}$, respectively. The $g_{i j}(r)$ for $\mathrm{Zr}-C_{\mathrm{w}}, \mathrm{O}-C_{\mathrm{w}}$ and $C_{\mathrm{w}}-C_{\mathrm{w}}$ (Fig. 4b) have maxima well below $1 \AA$, showing that $C_{\mathrm{w}} \mathrm{s}$ are close to $\mathrm{Zr}$ and $\mathrm{O}$ atoms. The ionic character of chemical bonding is clearly visible along $\mathrm{Zr}-\mathrm{O}$ bonds, where the associated WF centres (electron pairs from higher valence bands) are always close to oxygen and there are four $C_{\mathrm{w}} \mathrm{s}$ around each $\mathrm{O}$. In the high-temperature phase of $c-\mathrm{ZrO}_{2}$, the corresponding $C_{\mathrm{w}} \mathrm{s}$ are symmetrically aligned along $\mathrm{Zr}-\mathrm{O}$ bonds, as $\mathrm{O}$ is tetrahedrally coordinated by $\mathrm{Zr}$ (Fig. $4 \mathrm{~b}, \mathrm{O}-C_{\mathrm{w}}$ partial). The oxygen coordination is smaller $\left(N_{\mathrm{OZr}} \sim 3\right)$ and less regular in the liquid, and there is considerable scatter in both the $C_{\mathrm{w}}$ locations and spreads. The latter show (Fig. 4a, bottom panel) that WFs are considerably less localized than the crystalline reference value of $\sim 2.9$.

The highest occupied molecular orbital (HOMO) has been also visualized in Fig. 4c, where the KS orbital (HOMO) is delocalized over a group of atoms highlighted by a dashed circle, while the transformed WFs for HOMO and HOMO-1 ('molecular orbitals', Fig. 4d) are each localized over one $\mathrm{Zr}-\mathrm{O}$ bond. The WF shapes of these examples are very similar to those in the hightemperature phase of $c-\mathrm{ZrO}_{2}$, but there are also cases with considerable deviation, as can be expected from the scatter of WF spreads (Fig. 4a).

\section{Discussion}

The origin of FSDP associated with the formation of intermediate-range ordering in oxide glasses and liquids remains controversial, because the inherent disorder complicates the ability of AX polyhedral connections to form an A-X network. $\mathrm{SiO}_{2}$ has an exceptionally high glass-forming ability and the origin of FSDP in $\mathrm{SiO}_{2}$ has often been studied. The results are summarized in ref. 29. The random network model of Zachariasen $^{1}$ and modified for an oxide glass modified in refs 30,31 (illustrated in Fig. 7 of ref. 29) suggests that the intermediate-range ordering arises from the periodicity of boundaries between successive small cages in the network formed by connected, regular $\mathrm{SiO}_{4}$ tetrahedra with shared oxygen atoms at the corners. It has also been demonstrated that small cages are topologically disordered ${ }^{32}$, resulting in a broad distribution of ring sizes from 3 -fold to 12 -fold rings centred at 6-fold rings ${ }^{25,33}$. This is reflected in the $S_{\mathrm{NN}}(Q)$ of $l$-SiO ${ }_{2}$ (Fig. 2a), where the FSDP width is broader than that of the corresponding Bragg peak in the crystalline phase ( $\beta$-cristobalite, $c$ - $\mathrm{SiO}_{2}$ ), where only a sixfold ring donates. Figure $5 \mathrm{a}$,b show three-dimensional atomic configurations and schematic illustrations for $c-\mathrm{SiO}_{2}$ and $l-\mathrm{SiO}_{2}$, respectively. The crystalline phase exhibits only sixfold rings of $\mathrm{six}^{\mathrm{SiO}_{4}}$ tetrahedra, yielding a long-range periodicity (dashed cyan lines in Fig. 5a). However, some pseudo Bragg planes (dashed cyan lines in the left panel of Fig. 5b) can be recognized in $l-\mathrm{SiO}_{2}$. Although the introduction of different ring sizes can easily modify the crystalline topological order (Fig. 5b), the interconnection of regular $\mathrm{SiO}_{4}$ tetrahedra a
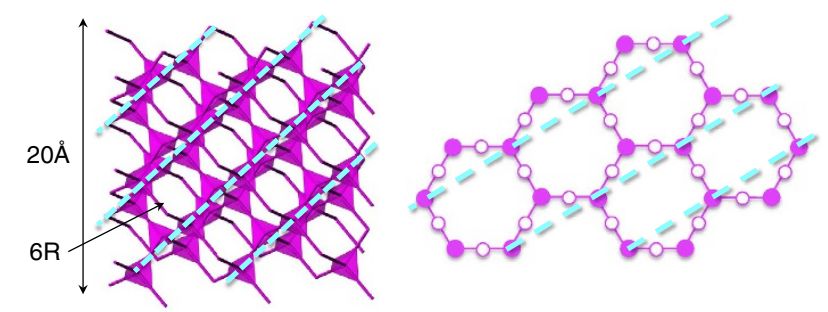

b
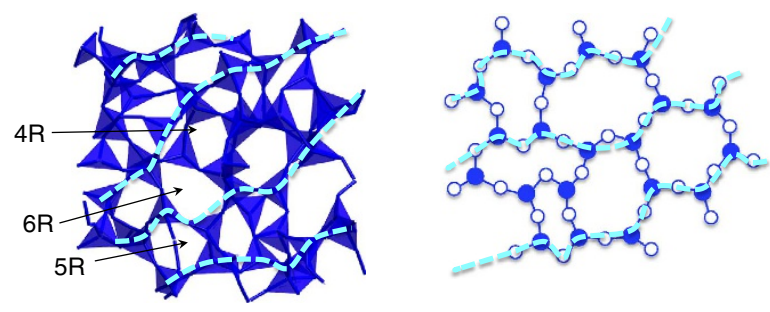

C
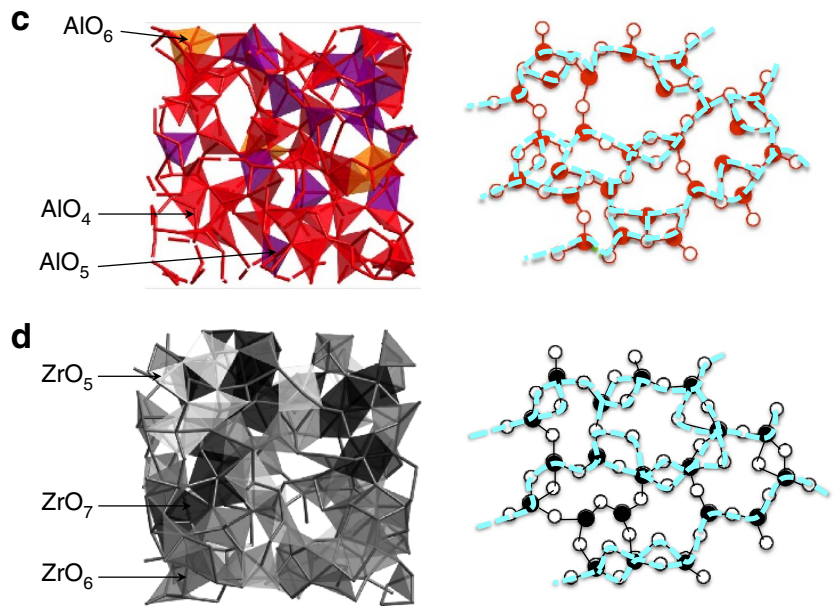

Figure 5 | The atomic structure of oxide liquids. (a) $\mathrm{c}-\mathrm{SiO}_{2}$ (for reference), (b) $1-\mathrm{SiO}_{2}$, (c) $1-\mathrm{Al}_{2} \mathrm{O}_{3}$ and (d) $1-\mathrm{ZrO}_{2}$. Colour code (right panels): $\mathrm{Si}$, magenta and blue spheres; $\mathrm{Al}$, red; $\mathrm{Zr}$, black; and $\mathrm{O}$, white. The periodicity of cage boundaries is highlighted by cyan dashed lines and curves.

with shared oxygen at corners only yields the broadened Bragg peak as FSDP.

In $l-\mathrm{Al}_{2} \mathrm{O}_{3}$, a considerable fraction of $\mathrm{AlO}_{5}$ units associated with the formation of $\mathrm{OAl}_{3}$ triclusters ${ }^{34}$ and the contribution of edge-sharing atoms (see Fig. $5 \mathrm{c})^{9}$ are necessary to compensate the negative charge of $\mathrm{AlO}_{4}$, because the nominal charge of the $\mathrm{Al}$ cation is three. We suggest that the variety of oxygen coordination (see Fig. 2b) and polyhedral sharing (Fig. 2c) disturb the formation of intermediate-range ordering in $l-\mathrm{Al}_{2} \mathrm{O}_{3}$. This is apparent in the absence of FSDP in the $S_{\mathrm{NN}}(Q)$ of $l-\mathrm{Al}_{2} \mathrm{O}_{3}$ in Fig. $2 \mathrm{a}$, despite the similarity between $l-\mathrm{SiO}_{2}$ and $l-\mathrm{Al}_{2} \mathrm{O}_{3}$ due to the predominant $\mathrm{AlO}_{4}$ units and corner sharing of oxygen in $l$ $\mathrm{Al}_{2} \mathrm{O}_{3}$ (note that the stoichiometry of $\mathrm{Al}_{2} \mathrm{O}_{3}$ is different from that of $\mathrm{SiO}_{2}$ ). The three-dimensional atomic configuration and schematic illustration of $l-\mathrm{Al}_{2} \mathrm{O}_{3}$ are illustrated in Fig. $5 c$, where the periodicity of boundaries is less obvious, due to the large contribution of $\mathrm{AlO}_{5}$ (purple polyhedra) and edge sharing of oxygen.

As can be seen in Fig. 2a, an FSDP is absent in the $S_{\mathrm{NN}}(Q)$ of $l$ $\mathrm{ZrO}_{2}$, because the variety of short-range structural units with large oxygen coordination, $\mathrm{ZrO}_{5}, \mathrm{ZrO}_{6}$ and $\mathrm{ZrO}_{7}$, and the large contribution of oxygen edge sharing prevents the formation of intermediate-range ordering. A similar feature can be expected in $l$ - $\mathrm{Y}_{2} \mathrm{O}_{3}$ and $l-\mathrm{La}_{2} \mathrm{O}_{3}$, because their Faber-Ziman partial structure factors, $S_{i j}(Q)$, do not contribute to the expected $Q$ position 
of $\sim 1 \AA^{-1}$ for a FSDP ${ }^{19}$. Short-range structural disordering in $l$ $\mathrm{ZrO}_{2}$ is further demonstrated in the three-dimensional atomic configuration and the schematic illustration of $l-\mathrm{ZrO}_{2}$ (Fig. $5 \mathrm{~d}$ ). The periodicity of boundaries (dashed cyan lines) is suppressed by the formation of edge-sharing of oxygen associated with the formation of $\mathrm{ZrO}_{5}$ (white polyhedra), $\mathrm{ZrO}_{6}$ (grey polyhedra) and $\mathrm{ZrO}_{7}$ (black polyhedra). Although $\mathrm{ZrO}_{2}$ forms a network structure by interconnecting AX polyhedra in the liquid phase, we have shown that the various short-range structural units and their connectivity cause disorder at the intermediate range and prevent the evolution of a FSDP in the liquid. Our results demonstrate that the absence of FSDP in $S_{\mathrm{NN}}(Q)$ can be an important indicator for single-component non-glass-forming oxide liquids, but it does not necessarily apply similarly to other non-GFLs.

Although $\mathrm{ZrO}_{2}$ and $\mathrm{Al}_{2} \mathrm{O}_{3}$ have different stoichiometries, the absence of FSDP in the $S_{\mathrm{NN}}(Q)$ suggests that they are both very 'fragile' liquids ${ }^{3}$. This suggestion is supported by a comparison with $l-\mathrm{ZnCl}_{2}$, which is recognized as an intermediate case between a 'strong' and 'fragile' liquid. $l-\mathrm{ZnCl}_{2}$ shows a well-defined, but not sharp, FSDP in the $S_{\mathrm{NN}}(Q)$ by the contribution of corner sharing of $\mathrm{ZnCl}_{4}$ tetrahedra, while edge sharing is also found ${ }^{35}$. This behaviour of 'fragile' glass former is very similar to $l-\mathrm{GeSe}_{2}$ where the FSDP in $S_{\mathrm{NN}}(Q)$ is weak, and a considerable fraction of edge sharing of $\mathrm{GeSe}_{4}$ tetrahedra contribute ${ }^{36}$, as in glassy $(g-)$ $\mathrm{GeSe}_{2}$ (ref. 37). We suggest that the liquid fragility increases with the contribution of edge sharing of tetrahedra, as discussed in ref. 38. However, the typical glass former $g-\mathrm{GeO}_{2}$ shows the contribution of only corner sharing of $\mathrm{GeO}_{4}$ tetrahedra ${ }^{33}$ that results in a sharp FSDP, while $g$-Ge-Te systems do not exhibit FSDP due to co-existing octahedral and tetrahedral Ge-Te polyhedra. Here the Te-Ge-Te bond angle distribution is peaked around $90^{\circ}$, quite different from $109.47^{\circ}$ of regular tetrahedra in $g-\mathrm{GeO}_{2}$ (refs 39-41). We conclude that the magnitude of the FSDP is sensitive to the variety in atomic coordination and polyhedral connections, which are connected in turn to the difference in ionic radii between constituent anions and cations.

The fragility of $l-\mathrm{ZrO}_{2}$ is confirmed by comparing the thermodynamic parameters of $l-\mathrm{ZrO}_{2}$ and $l-\mathrm{Al}_{2} \mathrm{O}_{3}$. Recent MD simulation for $l-\mathrm{Al}_{2} \mathrm{O}_{3}$ at $2,227^{\circ} \mathrm{C}^{42}$ reported a zero-frequency viscosity of $2.5 \times 10^{-2} \mathrm{Pas}^{-1}$, while the viscosity of $l-\mathrm{SiO}_{2}$ at $1,652{ }^{\circ} \mathrm{C}$ (a typical 'strong' liquid ${ }^{3}$ ) is $6.12 \times 10^{6} \mathrm{~Pa} \mathrm{~s}^{-1}$ (ref. 43). The zero-frequency viscosity value of $l-\mathrm{Al}_{2} \mathrm{O}_{3}$ is comparable to the results of the recent inelastic X-ray scattering measurement ${ }^{44}$ and the macroscopic shear viscosity of $3.3 \times 10^{-2} \mathrm{Pas}^{-1}$ at $2,213^{\circ} \mathrm{C}^{45}$, confirming that it is a 'fragile' liquid. The selfdiffusion coefficients for $\mathrm{Zr}$ and $\mathrm{O}$ in $l-\mathrm{ZrO}_{2}$ derived from our DF-MD simulations are $3.6 \times 10^{-5}$ and $7.1 \times 10^{-5} \mathrm{~cm}^{2} \mathrm{~s}^{-1}$, respectively, at $2,800^{\circ} \mathrm{C}$. The viscosity of $l-\mathrm{ZrO}_{2}$, estimated by assuming spherical particles and applying the Stokes-Einstein equation, is $\sim 2 \times 10^{-3} \mathrm{Pas} \mathrm{s}^{-1}$ at $2,800^{\circ} \mathrm{C}$, indicating that $l$ $\mathrm{ZrO}_{2}$ is an extremely fragile liquid. This conclusion is further supported by the $\mathrm{Zr}-\mathrm{O}$ bond lifetime analysis of $\mathrm{DF}-\mathrm{MD}$ simulations (Supplementary Note 2), which shows that $50 \%$ of the bonds break within $185 \mathrm{fs}$ at $2,800^{\circ} \mathrm{C}$ (Supplementary Fig. 5). The $\mathrm{Zr}-\mathrm{O}$ bond lifetime is extremely short when it is compared with the observation that the exchange-rate between bridging and non-bridging oxygen atoms in a silicate melt is within a nanosecond-to-microsecond time scale ${ }^{46}$. This behaviour of $\mathrm{Zr}$ $\mathrm{O}$ bonds is closely related to the variety of $\mathrm{ZrO}_{n}$ polyhedral units and polyhedral connections with a reduced electronic band gap and increased delocalization in the ionic $\mathrm{Zr}-\mathrm{O}$ bonding.

We study the atomic and electronic structure of non-glassforming $l-\mathrm{ZrO}_{2}$ with an extremely high melting point by using a combination of containerless processing, synchrotron X-ray diffraction, density measurements and DF-MD simulations.
Although a sharp peak is observed in the X-ray total structure factors, we find that FSDP is absent in the Bhatia-Thornton $S_{\mathrm{NN}}(Q)$. We show that the variety of short-range structural units with large oxygen coordination and their associated distortion due to edge sharing are signatures of single-component non-glass-forming oxide liquids. The absence of FSDP is ascribed to the variety of $\mathrm{ZrO}_{n}$ polyhedral units induced by the large ionic radius of $\mathrm{Zr}$ cation. This is reflected in the short lifetime of $\mathrm{Zr}-\mathrm{O}$ bonds (and polyhedral units), which prevents the evolution of intermediate-range ordering. These structural features are coupled to irregularity and reduced localization in the ionic $\mathrm{Zr}-\mathrm{O}$ bonds with short lifetime, yielding a reduced electronic band gap in $l-\mathrm{ZrO}_{2}$ and a low viscosity of the liquid. By comparing our results for $l-\mathrm{ZrO}_{2}$ with other GFLs, nonGFLs and glasses, we conclude that the absence of FSDP in the $S_{\mathrm{NN}}(Q)$, associated with a short lifetime of $\mathrm{Zr}-\mathrm{O}$ bonds and extremely low viscosity, is a feature of single-component nonglass-forming oxide liquids, although this does not necessarily apply to all non-GFLs. The DF-MD simulation results support the observed absence of FSDP and suggest that $l-\mathrm{ZrO}_{2}$ is an extremely fragile liquid. Finally, the containerless preparation and measurement techniques open up fresh capabilities to study new features in extremely high-temperature liquids, and we demonstrate the importance of combining experiment and theory to understand the nature of liquids at the atomistic (structure and dynamics) and electronic (chemical bonding) level.

\section{Methods}

Density measurement. The density measurement of $l-\mathrm{ZrO}_{2}$ was performed with an aerodynamic levitator ${ }^{6,47,48}$. A small $\mathrm{ZrO}_{2}$ sample whose diameter was around $2 \mathrm{~mm}$ was set in a shallow nozzle where the sample was aerodynamically levitated. The levitated sample was then heated by a $100-\mathrm{W} \mathrm{CO} 2$ laser and a $500-\mathrm{W}$ Nd:YAG laser. The temperature of the sample was measured by a single colour pyrometer. The weight of the recovered sample was measured. The temperature was calibrated using the given melting temperature $\left(T_{\mathrm{m}}=2,715^{\circ} \mathrm{C}\right)$ in density measurements. The details of measurement can be found in the Supplementary Note 3 and typical image of the levitated specimen and the density data is shown in Supplementary Figs 6 and 7, respectively.

High-energy X-ray diffraction measurement. The high-energy X-ray diffraction experiments of $l-\mathrm{ZrO}_{2}$ were carried out at the BL04B2 and the BL08W beamlines ${ }^{49}$ at the SPring- 8 synchrotron radiation facility, using the aerodynamic levitation technique ${ }^{6,47-49}$. The energy of the incident X-rays was $113 \mathrm{keV}$ (BL04B2) and $116 \mathrm{keV}$ (BL08W). The $\mathrm{ZrO}_{2}$ sample of $2-\mathrm{mm}$ size was levitated by dry air and heated by a $100-\mathrm{W} \mathrm{CO}_{2}$ laser. The temperature of the sample was monitored by a two-colour pyrometer. As can be seen in Supplementary Fig. 8, the background of the instrument was successfully reduced due to adequate shielding of the detector and the optimization of beam stop. The measured X-ray diffraction data were corrected for polarization, absorption and background, and the contribution of Compton scattering was subtracted using standard analysis procedures ${ }^{49}$. The corrected data sets were normalized to give the Faber-Ziman ${ }^{16}$ total structure factor $S(Q)$ and the total correlation function $T(r)$ was obtained by a Fourier transformation of $S(Q)$.

DF-MD simulation. The combined DF and MD simulations were performed with the $\mathrm{CP} 2 \mathrm{~K}$ programme package (http://www.cp2k.org) ${ }^{50}$. The CP2K method uses two representations for the KS orbitals and electron density: localized Gaussian and plane wave basis sets. For the Gaussian-based (localized) expansion of the KS orbitals, we used a library of contracted molecularly optimized valence double-zeta plus polarization basis sets ${ }^{51}$ and the complementary plane wave basis set for electron density has a cutoff of $400 \mathrm{Ry}$. The generalized gradient approximation of Perdew, Burke and Ernzerhof ${ }^{2}$ (PBE) was adopted for the exchange-correlation energy functional and the valence electron-ion interaction was based on the normconserving and separable pseudopotentials of the form derived by Goedecker et al. ${ }^{53} \mathrm{We}$ consider the following valence configurations: $\mathrm{Zr}\left(\mathrm{Cl}_{4} \mathrm{~s}^{2} 4 \mathrm{p}^{2} 5 \mathrm{~s}^{2} 5 \mathrm{~d}^{2}\right)$ and $\mathrm{O}\left(2 \mathrm{~s}^{2} 2 \mathrm{p}^{4}\right)$. Periodic boundary conditions were used, with a single point $(k=0)$ in the Brillouin zone. Effective charges of individual atoms were evaluated from electron density by integrating electronic charge inside the corresponding atomic volumes ${ }^{24}$. For reference, electronic structure of the high-temperature phase of $c$ $\mathrm{ZrO}_{2}\left(T>2,370^{\circ} \mathrm{C}\right)$ is computed for a sample of 324 atoms.

The initial atomic configuration is created by a reverse Monte Carlo (RMC) simulation with high-energy X-ray diffraction data on 501 atoms in a cubic box of $18.98 \AA$ (experimental density, 0.0733 atoms per $\AA^{3}$ ). The $\mathrm{RMC}++$ programme 
code $^{54}$ was used. The Born-Oppenheimer MD simulations were performed with a Nóse-Hoover thermostat ${ }^{55}$ and time steps of $2 \mathrm{fs}$ (initialization) and $1 \mathrm{fs}$ (data collecting). The system was simulated at $3,100 \mathrm{~K}\left(\sim 2,800^{\circ} \mathrm{C}\right)$ for a total of $30 \mathrm{ps}$, where the last $10 \mathrm{ps}$ were used for data collection ${ }^{55}$. The corresponding meansquare displacement of atoms shows clearly a liquid behaviour (diffusion). The comparison of the partial pair correlation functions, $g_{i j}(r)$, between the initial RMC configuration (start) and the DF-MD simulation is shown in Supplementary Fig. 9. The sharp shape of $\mathrm{O}-\mathrm{O} g_{\mathrm{ij}}(r)$ in the RMC model is artificially sharp due to small weighting factor for X-rays, while the shape of $\mathrm{O}-\mathrm{O} g_{\mathrm{ij}}(r)$ is reasonable in the DFMD simulations. The system lost its memory of the initial (RMC) starting structure within a few picoseconds $(\mathrm{Zr}-\mathrm{O}$ bond lifetimes $\sim 185 \mathrm{fs}$ ).

\section{References}

1. Zachariasen, W. H. The atomic arrangement in glass. J. Am. Chem. Soc. 54, 3841-3851 (1932)

2. Sun, K.-H. Fundamental condition of glass formation. J. Am. Ceram. Soc. 30, 277-281 (1947).

3. Angell, C. A. Formation of glasses from liquids and biopolymers. Science 267, 1924-1935 (1995).

4. Greaves, G. N. \& Sen, S. Inorganic glasses, glass-forming liquids and amorphizing solids. Adv. Phys. 56, 1-116 (2007).

5. Salmon, P. S. \& Zeidler, A. Identifying and characterising the different structural length scales in liquids and glasses: an experimental approach. Phys. Chem. Chem. Phys. 15, 15286-15308 (2013).

6. Price, D. L. High-Temperature Levitated Materials (Cambridge University Press, 2010).

7. Ansell, S. et al. Structure of liquid aluminum oxide. Phys. Rev. Lett. 78, 464-466 (1997).

8. Krishnan, S. et al. Structure of normal and supercooled liquid aluminum oxide. Chem. Mater. 17, 2662-2666 (2005).

9. Skinner, L. B. et al. Joint diffraction and modeling approach to the structure of liquid alumina. Phys. Rev. B 87, 024201 (2013).

10. Landron, C. et al. Liquid alumina: detailed atomic coordination determined from neutron diffraction data using empirical potential structure refinement. Phys. Rev. Lett. 86, 4839-4842 (2001).

11. Jahn, S. \& Madden, P. A. Structure and dynamics in liquid alumina: Simulations with an ab initio interaction potential. J. Non Cryst. Solids 353, 3500-3504 (2007).

12. Vashishta, P., Kalia, R. K., Nakano, A. \& Rino, J. P. Interaction potentials for alumina and molecular dynamics simulations of amorphous and liquid alumina. J. Appl. Phys. 103, 083504 (2008).

13. Wakasugi, T. et al. Thermal stability of RF-sputtered amorphous films in comparison with gels in the $\mathrm{SiO}_{2}-\mathrm{ZrO}_{2}$ system. Mater. Sci. Res. Int. 5, 38-44 (1999).

14. Rosenflanz, A., Tangeman, J. \& Anderson, T. On processing and properties of liquid phase derived glass ceramics in $\mathrm{Al}_{2} \mathrm{O}_{3}-\mathrm{La}_{2} \mathrm{O}_{3}-\mathrm{ZrO}_{2}$ system. Adv. Appl. Ceram. 111, 323-332 (2012).

15. Hsu, J.-Y. \& Speyer, R. F. Influences of zirconia and silicon nucleating agents on the devitrification of $\mathrm{Li}_{2} \mathrm{O} \cdot \mathrm{Al}_{2} \mathrm{O}_{3} \cdot 6 \mathrm{SiO}_{2}$ glasses. J. Am. Ceram. Soc. 73, 3585-3593 (1990).

16. Faber, T. E. \& Ziman, J. M. A theory of the electrical properties of liquid metals. Philos. Mag. 11, 153-173 (1965).

17. Mei, Q., Benmore, C. J. \& Weber, J. K. R. Structure of liquid $\mathrm{SiO}_{2}$ : a measurement by high-energy X-ray diffraction. Phys. Rev. Lett. 4, 057802 (2007).

18. Shannon, R. D. \& Prewitt, C. T. Effective ionic radii in oxides and fluorides. Acta Cryst. B25, 925-946 (1969).

19. Skinner, L. B. et al. Low cation coordination in oxide melts. Phys. Rev. Lett. 112, 157801 (2014).

20. Bhatia, A. B. \& Thornton, D. E. Structural aspects of the electrical resistivity of binary alloys. Phys. Rev. B 4, 3004-3012 (1971).

21. Salmon, P. S., Martin, R. A., Mason, P. E. \& Cuello, G. J. Topological versus chemical ordering in network glasses at intermediate and extended length scales. Nature 435, 75-78 (2005).

22. Takada, A., Richet, P., Catlow, C. R. A. \& Price, G. D. Molecular dynamics simulations of vitreous silica structures. J. Non Cryst. Solids 345\&346, 224-229 (2004).

23. Tomaszewski, P. E. Structural phase transitions in crystals. I. Database. Phase Transit. 38, 127-220 (1992).

24. Tang, W., Sanville, E. \& Henkelman, G. A grid-based Bader analysis algorithm without lattice bias. J Phys. Condens. Matter 21, 084204-084207 (2009).

25. Kohara, S. et al. Relationship between topological order and glass forming ability in densely packed enstatite and forsterite composition glasses. Proc. Natl Acad. Sci. USA 108, 14780-14785 (2011).

26. Akola, J. et al. Network topology for the formation of solvated electrons in binary $\mathrm{CaO}-\mathrm{Al}_{2} \mathrm{O}_{3}$ composition glasses. Proc. Natl Acad. Sci. USA 110, 10129-10134 (2013)
27. Marzari, N. \& Vanderbilt, D. Maximally localized generalized Wannier functions for composite energy bands. Phys. Rev. B 56, 12847-12865 (1997).

28. Resta, R. \& Sorella, S. Electron localization in the insulating state. Phys. Rev. Lett. 82, 370 (1999).

29. Mei, Q., Benmore, C. J., Sen, S., Sharma, R. \& Yargar, J. Intermediate range order in vitreous silica from a partial structure factor analysis. Phys. Rev. B 78, 144204 (2008).

30. Wright, A. C. Longer range order in single component network glasses? Phys Chem. Glasses 49, 103-117 (2008).

31. Price, D. L. et al. Short-, intermediate-, and extended-range order in rubidium germanate glasses. Phys. Rev. B 55, 11249-11255 (1997).

32. Gupta, P. K. \& Cooper, A. R. Topologically disordered networks of rigid polytopes. J. Non Cryst. Solids 123, 14-21 (1990).

33. Kohara, S. \& Suzuya, K. Intermediate-range order in vitreous $\mathrm{SiO}_{2}$ and $\mathrm{GeO}_{2}$. J. Phys. Condens. Matter 17, S77-S86 (2005).

34. Daniel, I., McMillan, P. F., Gilet, P. \& Poe, B. T. Raman spectroscopic study of structural changes in calcium aluminate $\left(\mathrm{CaAl}_{2} \mathrm{O}_{4}\right)$ glass at high pressure and high temperature. Chem. Geol. 128, 5-15 (1996).

35. Zeidler, A. et al. Structure of liquid and glassy $\mathrm{ZnCl}_{2}$. Phys. Rev. B 82, 104208-104217 (2010).

36. Salmon, P. S. Structure of liquids and glasses in the Ge-Se binary system. J. Non Cryst. Solids 353, 2959-2974 (2007).

37. Petri, I., Salmon, P. S. \& Fischer, H. E. Defects in a disordered world: The structure of glassy $\mathrm{GeSe}_{2}$. Phys. Rev. Lett. 84, 2413-2416 (2000).

38. Wilson, M. \& Salmon, P. S. Network topology and the fragility of tetrahedral glass-forming liquids. Phys. Rev. Lett. 103, 157801 (2009).

39. Matsunaga, T. et al. From local structure to nanosecond recrystallization dynamics in AgInSbTe phase-change materials. Nat. Mater. 10, 129-134 (2011).

40. Kalikka, J., Akola, J., Jones, R. O., Kohara, S. \& Usuki, T. Amorphous $\mathrm{Ge}_{15} \mathrm{Te}_{85}$ density functional, high-energy X-ray and neutron diffraction study. J. Phys. Condens. Matter 24, 015802 (2012).

41. Ohara, K. et al. The roles of the Ge-Te core network and the Sb-Te pseudo network during rapid nucleation-dominated crystallization of amorphous $\mathrm{Ge}_{2} \mathrm{Sb}_{2} \mathrm{Te}_{5}$. Adv. Func. Mater. 22, 2251-2257 (2012).

42. Jahn, S. \& Madden, P. A. Atomic dynamics of alumina melt: a molecular dynamics simulation study. Condens. Matter Phys. 11, 169-178 (2008).

43. Urbain, G., Bottinga, Y. \& Richet, P. Viscosity of liquid silica, silicates and alumino-silicates. Geochim. Cosmochim. Acta 46, 1061-1072 (1982).

44. Sinn, H. et al. Microscopic dynamics of liquid aluminum oxide. Science 299, 2047-2049 (2003).

45. Urbain, G. Viscosité de l'alumine liquide. Rev. Int. Hautes Temp. Refract. 19, 55-57 (1982)

46. Liu, S.-B., Stebbin, J. F., Schneider, E. \& Pines, A. Diffusive motion in alkali silicate melts: An NMR study at high temperature. Geochim. Cosmochim. Acto 52, 527-538 (1988)

47. Winborne, D. A., Nordine, P. C., Rosner, D. E. \& Marley, N. F. Aerodynamic levitation technique for containerless high temperature studies on liquid and solid samples. Metall. Trans. B 7B, 711-713 (1976).

48. Ishikawa, T., Paradis, P.-F. \& Yoda, S. New sample levitation initiation and imaging techniques for the processing of refractory metals with an electrostatic levitator furnace. Rev. Sci. Instrum. 72, 2490-2495 (2001).

49. Kohara, S. et al. Structural studies of disordered materials using high-energy $\mathrm{X}$-ray diffraction from ambient to extreme conditions. J. Phys. Condens. Matter 19, 506101 (2007).

50. VandeVondele, J. et al. QUICKSTEP: Fast and accurate density functional calculations using a mixed Gaussian and plane waves approach. Comput. Phys Commun. 167, 103-128 (2005).

51. VandeVondele, J. \& Hutter, J. Gaussian basis sets for accurate calculations on molecular systems in gas and condensed phases. J. Chem. Phys. 127, 114105-114109 (2007).

52. Perdew, J. P., Burke, K. \& Ernzerhof, M. Generalized gradient approximation made simple. Phys. Rev. Lett. 77, 3865-3868 (1996).

53. Goedecker, S., Teter, M. \& Hutter, J. Separable dual-space Gaussian pseudopotentials. Phys. Rev. B 54, 1703-1710 (1996).

54. Greben, O., Jóvári, P., Temleitner, L. \& Pusztai, L. A new version of the $\mathrm{RMC}++$ Reverse Monte Carlo program, aimed at investigating the structure of covalent glasses. J. Optoelectron. Adv. Mater. 9, 3021-3027 (2007).

55. Nose, S. A unified formulation of the constant temperature molecular dynamics methods. J. Chem. Phys. 81, 511-519 (1984).

\section{Acknowledgements}

Discussions with A. Takada, S. Takeda and M. Watanabe are gratefully appreciated. We are also grateful to A. Takada for providing $l$-SiO $\mathrm{Sita}_{2}$ and to J.W.E. Drewitt, S. Jahn and L. Hennet for providing $l-\mathrm{CaAl}_{2} \mathrm{O}_{4}$ data. We thank R.O. Jones for a critical reading of the manuscript. The synchrotron radiation experiments were carried out with the approval 
of the Japan Synchrotron Radiation Research Institute (Proposals 2009A1059, 2009B2100, 2009B2103, 2011A2050, 2011B1186, 2011B2087, 2012A1214, 2012B1183 and 2012B1974), and the DF-MD calculations were carried out on the Cray XT4/XT5 computers at CSC-the IT Center for Science Ltd, Finland, Juropa (Xeon 5570) computer in the Forschungszentrum Jülich, Germany, and Cray XC30 in Japan Advanced Institute of Science and Technology, Japan. This work was supported by a Grant-in-Aid for Scientific Research on Innovative Areas (24310075 and 24350111) from the Ministry of Education, Culture, Sports, Science and Technology of Japan. J.A. acknowledges financial support from the Academy of Finland through its Centres of Excellence Program (Project 251748).

\section{Author contributions}

S.K. and J.A. designed the research. S.K., K.O., M.I., J.Y., J.T.O., T.I, A. Mizuno, A. Masuno, Y.W. and T.U. performed experiments. J.A. and L.P. carried out DF-MD simulations. S.K., J.A., L.P., M.R. and A.F. analysed the data. S.K., J.A. and A.F. wrote the paper.

\section{Additional information}

Supplementary Information accompanies this paper at http://www.nature.com/ naturecommunications

Competing financial interests: The authors declare no competing financial interests.

Reprints and permission information is available online at http://npg.nature.com/ reprintsandpermissions/

How to cite this article: Kohara, S. et al. Atomic and electronic structures of an extremely fragile liquid. Nat. Commun. 5:5892 doi: 10.1038/ncomms6892 (2014).

(c) (i) This work is licensed under a Creative Commons Attribution 4.0 International License. The images or other third party material in this article are included in the article's Creative Commons license, unless indicated otherwise in the credit line; if the material is not included under the Creative Commons license, users will need to obtain permission from the license holder to reproduce the material. To view a copy of this license, visit http://creativecommons.org/licenses/by/4.0/ 